\title{
Análise espermática e testicular de touros Nelore suplementados com glicerina bruta
}

\author{
[Sperm and testicular analysis of Nellore bulls supplemented with crude glycerin]
}

\section{"Artigo Científico/Scientific Article"}

\author{
Evani Souza de Oliveira Strada ${ }^{1}$, Robério Rodrigues Silva ${ }^{2}$, Larissa Pires Barbosa ${ }^{1}$, \\ Gleidson Giordano Pinto de Carvalho ${ }^{3}$, Laudi Cunha Leite ${ }^{1}$, Meiby Carneiro de Paula Leite ${ }^{1}$, \\ Renan Luiz Albuquerque Vieira ${ }^{1}$, Dorgival Morais de Lima Júnior ${ }^{4 *}$
}

\author{
${ }^{1}$ Universidade Federal do Recôncavo da Bahia-UFRB, Cruz das Almas-BA, Brasil. \\ ${ }^{2}$ Universidade Estadual do Sudoeste da Bahia-UESB, Itapetinga-BA, Brasil. \\ ${ }^{3}$ Universidade Federal da Bahia-UFBA, Salvador-BA, Brasil. \\ ${ }^{4}$ Universidade Federal de Alagoas-UFAL, Arapiraca-AL, Brasil. \\ *Autor para correspondência/Corresponding author: E-mail: dorgival.junior@ arapiraca.edu.br
}

\section{Resumo}

Objetivou-se avaliar os efeitos da inclusão de glicerina bruta sobre a morfologia testicular de touros Nelore. Para isso, foram utilizados 35 bovinos com peso corporal inicial de 428,0 $\pm 32,11 \mathrm{~kg}$ e aproximadamente 22 meses, distribuídos em delineamento inteiramente casualizado, com cinco tratamentos e sete repetições, suplementados durante 88 dias, com 14 dias de adaptação. Os tratamentos consistiram na inclusão de glicerina de baixa pureza nos níveis de $0,3,6,9$ e $12 \%$ da matéria seca total dos suplementos. Foi realizado uma coleta de sêmen no $88^{\circ}$ dia experimental, posteriormente os animais foram pesados, abatidos e tiveram os testículos coletados, pesados e amostrados. A inclusão da glicerina bruta influenciou a motilidade e o vigor espermático $(\mathrm{P}<0,05)$. $\mathrm{O}$ peso corporal ao abate e perímetro escrotal não foram influenciados $(\mathrm{P}>0,05)$ pelos níveis de glicerina. Observou-se comportamento quadrático $(\mathrm{P}<0,05)$ para o índice Leydigossomático, com ponto de mínima de 6,66\% e para a proporção volumétrica das células de Leydig (CL), com ponto de mínima de 5,41\%. Não foram observadas alterações histopatológicas testiculares nos bovinos. A glicerina de baixa pureza promove modificações na motilidade e vigor espermático, no índice leydigossomático e no volume das células de Leydig. Portanto, não se recomenda a adição de glicerina bruta no suplemento de touros em atividade reprodutiva.

Palavras-chave: biodiesel; circunferência escrotal; fertilidade de ruminantes; glicerol.

\begin{abstract}
This study aimed to evaluate the effects of the inclusion of crude glycerin on the testicular morphology of Nellore bulls. For this, 35 bovines with initial body weight of $428.0 \pm 32.11 \mathrm{~kg}$ and approximately 22 months of age were used, distributed in a completely randomized design, with five treatments and seven repetitions, supplemented during 88 days, with 14 days of adaptation. The treatments consisted of the inclusion of low purity glycerin at levels $0,3,6,9$, and $12 \%$ of the total dry matter of the supplements. Semen collection was performed on the $88^{\text {th }}$ experimental day, after which the animals were weighed, slaughtered, and had their testicles collected, weighed, and sampled. The inclusion of crude glycerin influenced motility and sperm vigor $(\mathrm{P}<0.05)$. Slaughter body weight and scrotal circumference were not influenced $(\mathrm{P}>0.05)$ by glycerin levels. Quadratic behavior $(\mathrm{P}<0.05)$ was observed for the leydigosomatic index, with a minimum point of $6.66 \%$ and for the volumetric proportion of Leydig cells (LC), with a minimum point of $5.41 \%$. No testicular histopathological changes were observed in the cattle. Low purity glycerin promotes changes in sperm motility and vigor, leydigosomatic index and Leydig cell volume. Therefore, the addition of crude glycerin is not recommended to supplement bulls in reproductive activity.
\end{abstract}

Keywords: biodiesel; fertility; glycerol; scrotal circumference. 


\section{Introdução}

A glicerina bruta é um coproduto da indústria do biodiesel, resultado da transesterificação de gorduras utilizando catalizadores químicos. Tem aspecto físico de um líquido viscoso e apresenta na sua composição química principalmente glicerol e ácidos graxos, além de quantidades variáveis de $\mathrm{NaCl}$ e metanol (Beatriz et al., 2013; Oliveira et al., 2013).

Devido à riqueza em glicerol e gordura, a glicerina bruta vem sendo utilizada na alimentação animal como fonte de energia, substituindo o grão de milho nas rações (Silva et al., 2014; Lage et al., 2017). No metabolismo animal, o glicerol é convertido em glicose no fígado, via gliconeogênese, elevando o aporte energético para o animal (Ladeira et al., 2016). Em vacas, a oferta de glicerol incrementou a produção de insulina e, consequentemente, as taxas de concepção (León et al., 2010). Em machos mamíferos, no entanto, o próprio glicerol presente na glicerina bruta vem sendo descritos na literatura como inibidor da espermatogênese (Lopes e Silva, 2014).

O uso de glicerina bruta até $24 \%$ da matéria seca da dieta parece não provocar lesões histopatológicas no sistema nervoso central, rúmen, fígado, rins e intestinos de novilhos (Leão et al., 2012). Em relação ao sistema reprodutivo, a inclusão de até 7,5\% de glicerina bruta na dieta de machos ovinos parece segura, por não provocar lesões histopatológicas nos testículos de ovinos (Santos et al., 2016). No entanto, estudos avaliando a morfologia e patologia testicular de bovinos alimentados com níveis mais elevados de glicerina bruta são escassos na literatura.

Desta forma, objetivou-se avaliar o efeito da inclusão de glicerina bruta sobre a morfologia testicular de touros Nelore terminados em pastagem.

\section{Materiais e Métodos}

O estudo foi realizado no Setor de Bovino de Corte da Universidade Federal do Recôncavo da Bahia (UFRB), Campus de Cruz das Almas BA, em uma área de 35 hectares (ha) formada de Urochloa decumbens, dividida em cinco piquetes com aproximadamente sete ha cada, com acesso ao cocho para suplementação.

Utilizou-se 35 bovinos touros Nelore, com peso corporal inicial médio de $428,0 \pm 32,11 \mathrm{~kg}$ e aproximadamente 22 meses de idade, distribuídos em um delineamento inteiramente casualizado, com cinco tratamentos e sete repetições cada. $\mathrm{O}$ período experimental foi 88 dias, sendo os primeiros 14 dias destinados à adaptação dos animais ao manejo e as dietas experimentais.

Os animais foram suplementados na proporção de $1,0 \%$ do peso corporal. Os suplementos continham $0,3,6,9$ e $12 \%$ de inclusão de glicerina de baixa pureza na matéria seca total, sendo formuladas segundo o NRC (2000) (Tabela 1), para atender as exigências de mantença e ganho médio diário (GMD) de $1,2 \mathrm{~kg}$ e fornecidos diariamente às 11 horas.

Tabela 1. Composição percentual dos suplementos com base na matéria seca e composição química dos suplementos e pasto ofertados.

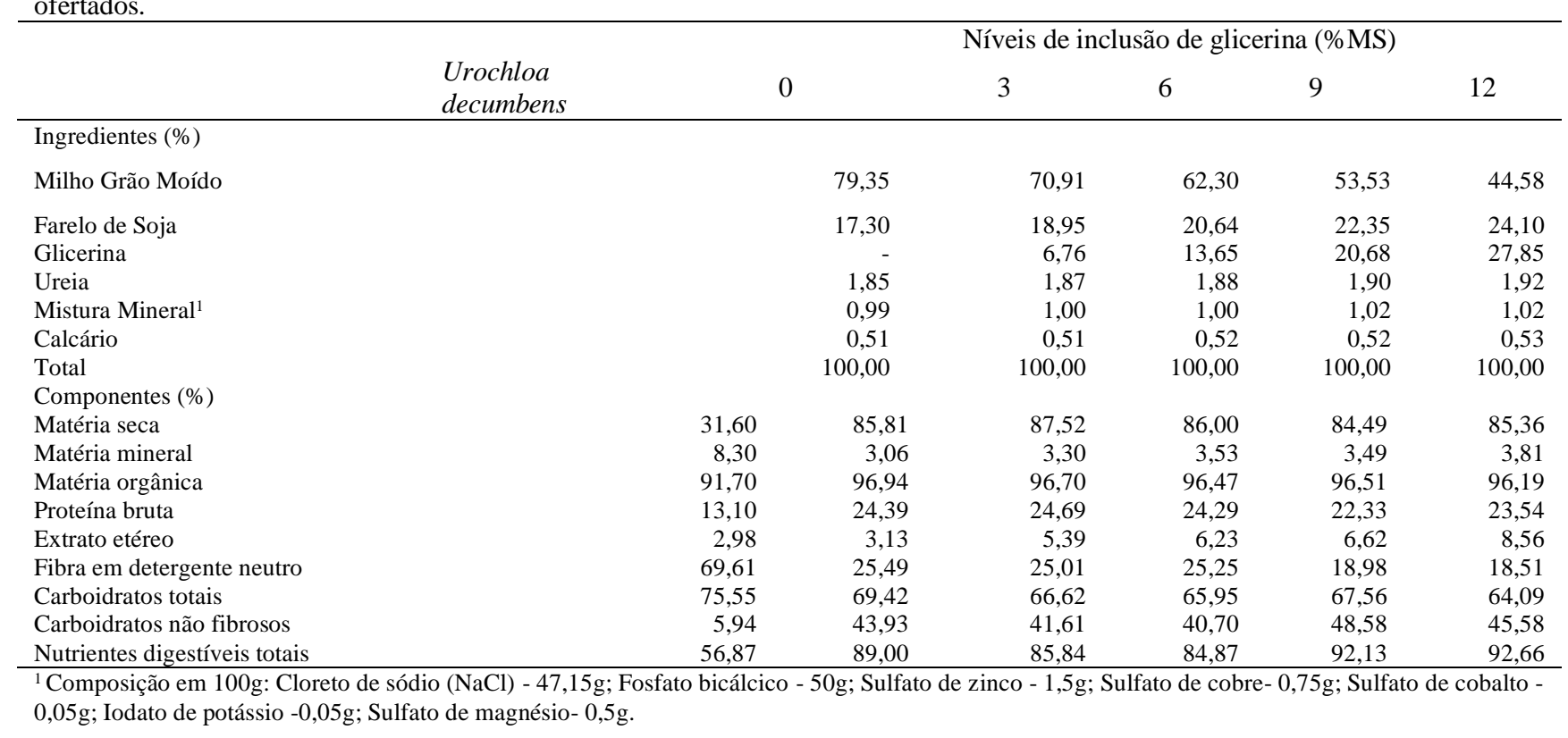


Para evitar possíveis efeitos dos piquetes, especialmente quanto à disponibilidade e qualidade da forragem e a eliminação de possíveis efeitos de ambiente sobre os tratamentos, os animais juntamente com os tratamentos foram rotacionados entre os piquetes a cada sete dias.

As amostras da forragem e dos suplementos foram analisadas para a determinação dos teores de matéria seca (MS), proteína bruta (PB) e extrato etéreo (EE) segundo Silva e Queiroz (2002); fibra em detergente neutro (FDN) e matéria mineral ou cinzas, segundo Van Soest et al. (1991). O teor de matéria orgânica (MO) foi estimado a partir da subtração do teor de cinzas do valor de MS.

A composição físico-química da glicerina foi realizada pelo método de Karl Fischer no Instituto de Tecnologia do Paraná - TECPAR, Curitiba - PR. Os resultados em porcentagem na matéria natural foram: $43,9 \%$ de glicerol, $6,0 \%$ de metanol, 33,6\% de ácidos graxos totais, 9,0\% de água e $7,3 \%$ de matéria mineral.

Ao $88^{\circ}$ dia experimental, os animais foram contidos no centro de manejo e foram retiradas amostras de sangue, sêmen e medição da circunferência escrotal. As amostras de sangue $(5 \mathrm{~mL})$ foram obtidas por venopunção jugular, utilizando tubos a vácuo contendo como anticoagulante EDTA. Após a coleta, em temperatura ambiente, o sangue foi centrifugado a $3.000 \mathrm{rpm}$, por 15 minutos, e o plasma sanguíneo foi armazenado e congelado a $-20^{\circ} \mathrm{C}$, até a realização da dosagem de testosterona pelo método de quimioluminescência, utilizando o kit comercial Access Testosterone da Beckman Coulte ${ }^{\circledR}$, seguindo as orientações recomendadas pelo fabricante. Para avaliação da qualidade física e morfológica seminal, a coleta foi realizada por meio da eletroejaculação (Torjet 65, Eletrovet, São Paulo). Após a coleta, o tubo coletor foi acondicionado em banho-maria, a $37^{\circ} \mathrm{C}$, e submetido a exame para determinação do volume do ejaculado $(\mathrm{mL})$, aspecto seminal, turbilhonamento (0-5), motilidade progressiva (0$100 \%)$, vigor (0-5) e concentração espermática. A avaliação da concentração espermática, foi determinada em câmara de Neubauer (Henry e Neves, 1998), enquanto a morfologia espermática foi avaliada após adição de uma alíquota de sêmen fresco a solução formol salina (Hancock, 1957) em microscopia (Microscópio Olympus BX53F Tokyo Japão) de interferência diferencial de fase. A aferição da biometria testicular, em centímetros, foi obtida com fita métrica metálica, tomada na região de maior envergadura com os testículos posicionados simetricamente na bolsa escrotal, conforme o CBRA (1998).

Ao final do período experimental os animais foram pesados, após um jejum de sólidos de 14 horas, e destinados a um frigorífico comercial para a realização do abate. Após o abate, os testículos foram coletados, identificados como direito e esquerdo, removendo-se o epidídimo, e pesados em balança digital. Foram coletadas três amostras de parênquima testicular esquerdo, medindo $1,0 \times 1,0$ $\mathrm{x} 0,5 \mathrm{~cm}$, nas regiões apical, média e distal; em seguida, as amostras foram acondicionadas em recipiente plástico contendo formol tamponado a $10 \%$, para avaliação histopatológica. O processamento histológico foi realizado segundo Luna (1998).

Para determinação dos parâmetros de morfometria testicular foi utilizado a média das três amostras colhidas. O diâmetro tubular médio foi obtido a partir da mensuração de 20 seções transversais do túbulo seminífero por animal, independentemente do estádio do ciclo do epitélio seminífero. As seções foram escolhidas ao acaso mediante varredura horizontal, sendo utilizadas para mensuração do diâmetro tubular aquelas que apresentavam o contorno o mais circular possível. As mensurações foram feitas com o auxílio de ocular micrométrica 10X e objetiva de $10 \mathrm{X}$ em microscópio óptico (Microscópio Olympus BX53F - Tokyo Japão) conforme metodologia descrita por Silva et al. (2015).

$\mathrm{O}$ índice gonadossomático (IGS), que representa o percentual da massa corporal alocado em testículo, foi calculado dividindo-se o peso médio dos dois testículos pelo peso corporal. Os índices leydigossomático (ILS) e tubulossomático (ITS) representam o percentual da massa corporal alocado, respectivamente, em células de Leydig e túbulos seminíferos. Os quais foram calculados inferindo-se do IGS o percentual do parênquima testicular ocupado pelas células de Leydig e pelos túbulos seminíferos. ILS=(vtcl/pc) $\times 100$. Em que ILS = índice leydigossomático; $\mathrm{vtcl}=$ volume total de células de Leydig; e pc = peso corporal. Os resultados referentes aos IGS, ILS e ITS foram expressos em percentual.

Os dados foram avaliados por meio de análises de variância através do teste $\mathrm{F}$ e os modelos de regressão a analisados pelo teste $\mathrm{t}$, utilizando-se o programa de análises estatísticas SAS. Os modelos estatísticos foram escolhidos de 
acordo com a significância dos coeficientes de regressão ao nível de $5 \%$ de probabilidade.

\section{Resultados}

Considerando o consumo de suplemento e o teor de glicerina no mesmo, a quantidade consumida de glicerina bruta pelos animais foi de $0 \mathrm{~g} ; 0,31 \mathrm{~kg} ; 0,53 \mathrm{~kg} ; 1,0 \mathrm{~kg}$ e $1,1 \mathrm{~kg} / \mathrm{dia}$ para os níveis de $0,3,6,9,12 \%$ de glicerina na matéria seca da dieta.

Com relação aos resultados dos aspectos físicos seminais, não foram observados efeitos $(\mathrm{P}<0,05)$ da dieta sobre o volume seminal e concentração espermática. Entretanto, para as variáveis de motilidade espermática progressiva e vigor espermático, houve efeito quadrático negativo (Tabela 2). A motilidade e o vigor espermáticos apresentaram melhores respostas, quando o nível de glicerina foi de 5,38\% e 5,56\%, respectivamente.

A inclusão de glicerina não teve efeito $(\mathrm{P}>0,05)$ sobre o peso corporal ao abate (PCA), circunferência escrotal (CE), peso dos testículos (esquerdo e direito) ou sobre o índice gonadossomático. No entanto, observamos efeito $(\mathrm{P}<0,05)$ da inclusão do coproduto do biodiesel sobre o indicie leydigossomático (Tabela 3).

Tabela 2. Aspectos físicos e morfológicos do sêmen fresco de touros suplementados com glicerina de baixa pureza em pastagem de Urochloa decumbens.

\begin{tabular}{|c|c|c|c|c|c|c|c|c|}
\hline \multirow[t]{2}{*}{ Variáveis } & \multicolumn{5}{|c|}{ Níveis de inclusão de glicerina (\%MS) } & \multirow[t]{2}{*}{$\mathrm{EPM}^{1}$} & \multicolumn{2}{|c|}{ P Valor ${ }^{2}$} \\
\hline & 0 & 3 & 6 & 9 & 12 & & $\mathrm{~L}$ & Q \\
\hline $\mathrm{VOL}(\mathrm{mL})^{\#}$ & 7,60 & 8,07 & 11,94 & 8,23 & 6,52 & 0,33 & 0,70 & 0,34 \\
\hline TUR & 0,71 & 0,53 & 1,10 & 0,67 & 0,17 & 0,08 & 0,15 & $0,08^{*}$ \\
\hline MOT $(\%)$ & 64,42 & 71,42 & 86,78 & 75,35 & 48,57 & 3,79 & 0,33 & $0,008^{* *}$ \\
\hline VIG & 3,35 & 3,10 & 4,53 & 3,89 & 2,42 & 0,19 & 0,47 & $0,02 *$ \\
\hline $\mathrm{CON}\left(\mathrm{x} 10^{6} \mathrm{sptz} \mathrm{mL}\right)$ & 6190,27 & 2341,16 & 8345,20 & 5824,09 & 2907,90 & 855,40 & 0,24 & 0,1 \\
\hline $\operatorname{DME}(\%)$ & 10,57 & 3,85 & 13,50 & 2,85 & 11,85 & 2,17 & 0,87 & 0,94 \\
\hline DT $(\%)$ & 23,28 & 23,78 & 37,21 & 26,57 & 24,28 & 3,34 & 0,82 & 0,99 \\
\hline
\end{tabular}

${ }^{1} \mathrm{EPM}=$ erro padrão da média; ${ }^{2} \mathrm{~L}$ e Q: ordem dos efeitos linear e quadrático para a inclusão da glicerina de baixa pureza na dieta; ${ }^{\# V O L: ~ v o l u m e ; ~ T U R: ~}$ turbilhonamento (escala de 0-5); MOT: motilidade espermática progressiva; VIG: vigor (escala de 0-5); CON: concentração espermática; DME: defeitos menores; DMA: defeitos maiores; DT: defeitos totais. ${ }^{*} \hat{Y}=-0,74887 \mathrm{x}^{2}+8,06020 \mathrm{x}+61,39184\left(\mathrm{R}^{2}=25,0\right) ;{ }^{* *} \hat{\mathrm{Y}}=-0,03571 \mathrm{x}^{2}+0,39286 \mathrm{x}+3,03571\left(\mathrm{R}^{2}=\right.$ $21,0)$.

Tabela 3. Biometria e morfometria testicular de touros suplementados com glicerina de baixa pureza em pastagem de Urochloa decumbens.

\begin{tabular}{|c|c|c|c|c|c|c|c|c|}
\hline \multirow[t]{2}{*}{ Variáveis } & \multicolumn{5}{|c|}{ Níveis de inclusão de glicerina (\%MS) } & \multirow[t]{2}{*}{$\mathrm{EPM}^{1}$} & \multicolumn{2}{|c|}{ P Valor ${ }^{2}$} \\
\hline & 0 & 3 & 6 & 9 & 12 & & $\mathrm{~L}$ & Q \\
\hline PCA $(\mathrm{kg})^{\#}$ & 508,57 & 494,71 & 529,71 & 531,57 & 526,28 & 7,72 & 0,199 & 0,80 \\
\hline $\mathrm{CE}(\mathrm{cm})$ & 35,07 & 32,71 & 35,25 & 34,96 & 32,00 & 0,46 & 0,20 & 0,24 \\
\hline PTD (g) & 289,0 & 212,0 & 262,0 & 279,0 & 248,0 & 9,28 & 0,90 & 0,88 \\
\hline PTE (g) & 266,0 & 208,0 & 252,0 & 288,0 & 241,0 & 9,63 & 0,64 & 0,88 \\
\hline $\operatorname{IGS}(\%)$ & 0,10736 & 0,08501 & 0,09707 & 0,10881 & 0,09345 & 0,0032 & 0,89 & 0,88 \\
\hline $\operatorname{ILS}(\%)$ & 0,00295 & 0,00201 & 0,00185 & 0,00190 & 0,00275 & 0,0001 & 0,79 & $0,004 * *$ \\
\hline $\operatorname{ITS}(\%)$ & 0,04306 & 0,03411 & 0,03964 & 0,04361 & 0,03690 & 0,0013 & 0,79 & 0,93 \\
\hline $\mathrm{CTT}(\mathrm{m})$ & $19.302,4$ & $14.114,2$ & $20.843,0$ & $18.981,0$ & $15.854,0$ & 769,15 & 0,74 & 0,94 \\
\hline CTGT $(\mathrm{m} / \mathrm{g})$ & 35,21 & 33,09 & 35,63 & 33,48 & 32,48 & 0,75 & 0,35 & 0,60 \\
\hline DTS $(\mu \mathrm{m})$ & 273,33 & 259,00 & 273,14 & 261,66 & 257,57 & 4,28 & 0,30 & 0,59 \\
\hline $\operatorname{AES}(\mu \mathrm{m})$ & 70,33 & 67,00 & 72,71 & 68,83 & 68,00 & 1,30 & 0,77 & 0,86 \\
\hline
\end{tabular}

${ }^{1} \mathrm{EPM}=$ erro padrão da média; ${ }^{2} \mathrm{~L}$ e Q: ordem dos efeitos linear e quadrático para a inclusão da glicerina de baixa pureza na dieta; ${ }^{\#} \mathrm{PCA}:$ peso corporal ao abate; $\mathrm{CE}=$ circunferência escrotal; PTD = peso testículo direito; PTE = peso testículo esquerdo ; IGS = indicie gonadossomático; ILS = indicie leydigossomático; ITS = indicie tubulossomático; CTT = comprimento total dos túbulos seminíferos; CTGT = comprimento total dos túbulos seminíferos por grama de testículo; DTS = diâmetro dos túbulos seminíferos; AES= altura do epitélio seminífero; ${ }^{* *} \hat{Y}=0,000264999 x^{2}-0,00164 x+0,00430\left(R^{2}=0,30\right)$.

A substituição do milho por glicerina bruta não influenciou $(\mathrm{P}>0,05)$ o indicie tubulossomático (ITS), comprimento total dos túbulos seminíferos (CTT), diâmetro dos túbulos seminíferos (DTS) ou altura do epitélio seminífero (AES) dos testículos dos touros.

Similarmente ao índice leydigossomático, a proporção volumétrica de células de Leydig (CL) foi influenciada $(\mathrm{P}<0,05)$ pelo uso da glicerina bruta (Tabela 4).

Apesar da inclusão da glicerina no suplemento estar associada à redução do volume de células de Leydig, a concentração plasmática de testosterona dos touros não foi afetada pelos tratamentos (Figura 1). 
Tabela 4. Proporção volumétrica (\%) dos componentes do parênquima testicular de touros suplementados com glicerina de baixa pureza em pastagem de Urochloa decumbens.

\begin{tabular}{|c|c|c|c|c|c|c|c|c|}
\hline \multirow{2}{*}{ Variáveis } & \multicolumn{5}{|c|}{ Níveis de inclusão de glicerina (\%MS) } & \multirow[t]{2}{*}{$\mathrm{EPM}^{1}$} & \multicolumn{2}{|c|}{ P Valor ${ }^{2}$} \\
\hline & 0 & 3 & 6 & 9 & 12 & & $\mathrm{~L}$ & Q \\
\hline Tunica própria & 9,04 & 8,53 & 9,43 & 9,50 & 8,64 & 0,32 & 0,964 & 0,850 \\
\hline Epitélio seminífero & 50,51 & 53,37 & 57,70 & 56,88 & 56,51 & 1,29 & 0,104 & 0,147 \\
\hline Lúmen tubular & 24,71 & 24,20 & 19,53 & 21,41 & 19,36 & 1,07 & 0,075 & 0,193 \\
\hline Túbulo seminífero & 84,27 & 86,10 & 86,67 & 87,79 & 84,52 & 0,75 & 0,665 & 0,061 \\
\hline Célula de Leyding & 5,88 & 5,05 & 4,10 & 3,95 & 6,21 & 0,27 & 0,978 & $0,005^{*}$ \\
\hline Vasos sanguíneos & 0,42 & 0,36 & 0,24 & 0,26 & 0,30 & 0,02 & 0,089 & 0,053 \\
\hline Tecido conjuntivo & 9,24 & 8,69 & 8,66 & 7,95 & 8,93 & 0,28 & 0,565 & 0,528 \\
\hline Espaço intertubular & 15,54 & 14,11 & 13,00 & 12,18 & 15,45 & 0,75 & 0,664 & 0,057 \\
\hline
\end{tabular}

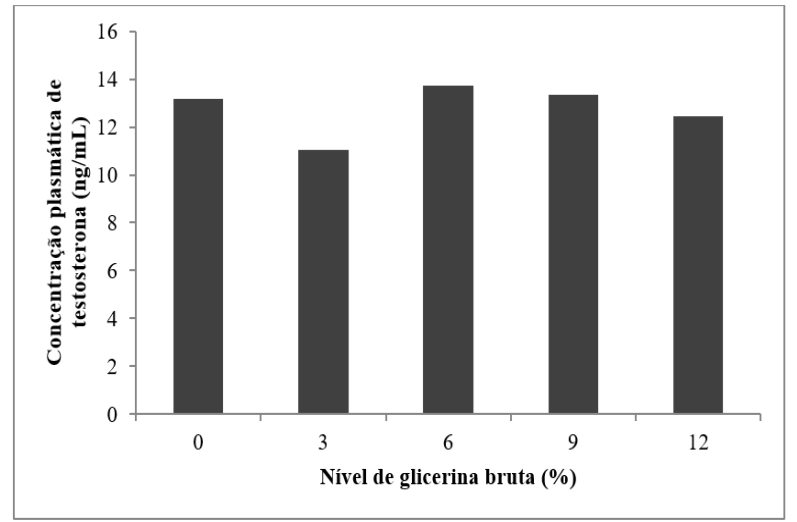

Figura 1. Concentração plasmática de testosterona $(\mathrm{ng} / \mathrm{mL})$ de touros a pasto alimentados com níveis crescentes de glicerina bruta no suplemento. Não foi verificada diferença significativa $(\mathrm{P}>0,05)$ entre os tratamentos. Os dados estão expressos em médias e possuem um erro padrão de 0,63 .

\section{Discussão}

A motilidade e o vigor espermáticos apresentaram melhores respostas, quando o nível de glicerina foi de $5,38 \%$ e $5,56 \%$, respectivamente. Dessa forma, níveis superiores a $5,4 \%$ de glicerina bruta na dieta de touros podem reduzir a fertilidade por comprometer o vigor e a motilidade espermática. Gomes (2009) também observou que a inclusão da glicerina na dieta comprometeu o vigor espermático do sêmen de carneiros.

O PCA e a CE dos touros tiveram média de $518 \mathrm{~kg} \mathrm{e} 34 \mathrm{~cm}$, respectivamente, e não foram influenciados $(\mathrm{P}>0,05)$ pela inclusão da glicerina bruta na dieta. Existe correlação alta e positiva $(0,71)$ entre o peso corporal e a circunferência escrotal de touros (Dias et al., 2008). O peso dos testículos direito e esquerdo juntos equivaleu, em média, a $0,51 \mathrm{~kg}$ e não diferiu $(\mathrm{P}>0,05)$ entre as dietas. O índice gonadossomático (IGS) - que representa a massa corporal alocada nos testículos - teve média de $0,098 \%$ e também não foi influenciado $(\mathrm{P}>0,05)$ pela adição de glicerina bruta na dieta dos touros.

A inclusão da glicerina bruta na dieta dos touros influenciou $(\mathrm{P}<0,05)$ de forma quadrática $(\hat{\mathrm{Y}}$ $=0,000264999 \times 2-0,00164 \mathrm{x}+0,00430, \mathrm{R}^{2}=0,30$ ) o índice leydigossomático (ILS). Considerando a ausência de efeito da inclusão da glicerina sobre o PCA pode-se então atribuir o efeito sobre ILS ao volume total de células de Leydig no testículo dos bovinos. Sugere-se que o incremento no teor de gordura das dietas (saindo de 3,13\% para 8,56\%) e, segundo Cui e Guam (2016) o excesso de gordura dietética reduz a capacidade de proliferação das células de Leydig.

$\mathrm{O}$ excesso de gordura dietética também foi apontado por Campos-Silva et al. (2015) como responsáveis pela redução da altura do epitélio do túbulo seminífero e do diâmetro dos túbulos seminíferos. No entanto, não observamos efeito $(\mathrm{P}>0,05)$ da inclusão da glicerina bruta sobre o diâmetro ou altura do epitélio dos túbulos seminíferos do testículo de bovinos. Resultado similar foi relatado por Santos et al. (2016) que reportaram ausência de efeito da glicerina bruta sobre diâmetro ou altura do epitélio dos túbulos seminíferos no testículo de ovinos

O glicerol é conhecido pelo seu efeito esclerosante (formação de tecido cicatricial conjuntivo no parênquima tissular) quando aplicado diretamente nos testículos de mamíferos (Lopes e Silva, 2014). Aqui os animais consumiram o máximo de $1 \mathrm{~kg}$ de glicerina bruta e $440 \mathrm{~g}$ de glicerol (considerando teor de $44 \%$ de glicerol na glicerina). Esse álcool é rapidamente fermentado pelos micro-organismos ruminais em propionato (van Cleef et al., 2015). O glicerol pode ainda ser absorvido diretamente pela mucosa ruminal e, dessa forma, ser metabolizado no tecido hepático à glicose (Kozloski et al., 2001). Nesse contexto, é pouco provável que o glicerol tenha 
alcançado o testículo dos bovinos e provocado lesão apenas nas células de Leydig. Essa hipótese é validada pela ausência de efeito das dietas $(\mathrm{P}>0,05)$ sobre a proporção de túbulos seminíferos e espaço intertubular do testículo dos bovinos.

O nível de testosterona plasmática dos touros apresentou média de $12,74 \mathrm{ng} / \mathrm{mL}$ e não foi influenciado $(\mathrm{P}>0,05)$ pela adição de glicerina bruta às dietas. A aplicação intratesticular de glicerol em garanhões reduziu a espermatogênese, porém, de forma similar a nossas observações, não influenciou os níveis plasmáticos de testosterona (Jung e Yoon, 2017). Podemos inferir que, apesar da redução no volume ocupado de células de Leydig promovido pelas células de gordura, esse decréscimo não foi suficiente para interferir na produção de testosterona dos touros.

\section{Conclusão}

A inclusão de glicerina de baixa pureza no suplemento de touros promove modificações na motilidade e vigor espermático, no índice leydigossomático e no volume das células de Leydig. Não se recomenda a adição de glicerina bruta na dieta de touros em atividade reprodutiva.

\section{Agradecimentos}

A UFRB/ Campus de Cruz das Almas, BA, a UESB/Campus de Itapetinga, BA, e a FAPESB.

\section{Declaração de conflito de interesses \\ Não existe conflito de interesse.}

\section{Comitê de Ética}

O projeto foi aprovado pelo comitê de ética no uso de animais (CEUA) da Universidade Estadual do Sudeste da Bahia (UESB) através do protocolo CEUA 17/2012.

\section{Referências}

Beatriz, A.; Araújo, Y.J.K.; Lima, D.P. Glicerol: um breve histórico e aplicação em sínteses estereosseletivas. Química Nova, 34(2):306319, 2011.

Campos-Silva, P.; Furriel, A.; Costa, W.S.; Sampaio, F.J.B.; Gregório, B.M. Metabolic and testicular effects of the long-term administration of different high-fat diets in adult rats. International Brazilian Journal of Urology, 41(3):569-575, 2015.

CBRA. Manual para exame andrológico e avaliação de sêmen animal. $2^{\mathrm{a}}$.ed. Colégio
Brasileiro de Reprodução Animal. Belo Horizonte, Minas Gerais, 1998.

Cui, L.; Guan, Q. Regulation of lipid metabolism in rat leydig cells testosterone synthesis and proliferation. International Journal of Clinical and Experimental Medicine, 9(5):8224-8229, 2016.

Dias, J.C.; Andrade, V.J.; Martins, J.A.M.; Emerick, L.L., Vale Filho, V.R. Correlações genéticas e fenotípicas entre características reprodutivas e produtivas de touros da raça Nelore. Pesquisa Agropecuária Brasileira, 43(1):53-59, 2008.

Hancock, J. L. The morphology of boar espermatozoa. Journal of Reproductive Microscopy Society, 76(1):84-97, 1957.

Henry, M.; Neves, J. P. Manual para exame andrológico e avaliação de sêmen animal. $2^{\mathrm{a}}$ ed. Belo Horizonte: EMBRAPA, 1998. 53p.

Immegart, H.M.; Threlfall, W.R. Evaluation of intratesticular injection of glycerol for nonsurgical sterilization of dogs. American Journal of Veterinary Research, 6(1):544549, 2000.

Jung, H.; Yoon, M. Effects of Intratesticular Injection of $70 \%$ Glycerin on Stallions. Journal of Equine Veterinary Science, 49(1):1-10, 2017.

Kozloski, G.V.; Rocha, J.B.T.; Ciocca, M.L.S. Metabolismo visceral e eficiência do uso da energia pelos ruminantes. Ciência Rural, 31(5):321-327, 2001.

Ladeira, M.M.; Carvalho, J.R.R.; Chizzotti, M.L.; Teixeira, P.D.; Dias, J.C.O.; Gionbelli, T.R.S.; Rodrigues, A.C.; Oliveira, D.M. Effect of increasing levels of glycerin on growth rate, carcass traits and liver gluconeogenesis in young bulls. Animal Feed Science and Technology, 219(3):241-248, 2016.

Lage, J.F.; Vito, E.S.; Reis, R.A.; Delevatti, L.M.; Pierre, N.S.; Berchielli, T.T. Ruminal fermentation of Nellore steers fed crude glycerine replacing starch vs. fibre-based energy ingredient in low or high concentrate diets. Acta Scientiarum Animal Science, 39(1):57-64, 2017.

Leão, J.P.; Ramos, A.T.; Maruo, V.M. Anatomopatologia de amostras de bovinos alimentados com glicerol. Ciência Rural, 42(7):1253-1256, 2012.

León, A.O.; Cerón, J.H.; Gutiérrez, C.G. La administración oral de glicerol después de la inseminación incrementa el porcentaje de 
concepción en vacas. Revista Mexicana de Ciências Pecuárias, 1(1):69-74, 2010.

Lopes, K.R.F.; Silva, A.R. Castração química de mamíferos machos: revisão. Revista Brasileira de Reprodução Animal, 38(1):49-53, 2014.

Luna, L.G. Manual of histology stainig methods of the Armed Forces Institute of Pathology. $3^{\text {rd }}$. New York: McGraw-Hill Book Company, 1968. 258p.

National Research Council-NRC. Nutrient requirements of dairy cattle. $7^{\text {th }}$ ed. Washington: National Academy Press, 2000. 401p.

Oliveira, J.S.; Antoniassi, R.; Freitas, S.C.; Müller, M.D. Composição química da glicerina produzida por usinas de biodiesel no Brasil e potencial de uso na alimentação animal. Ciência Rural, 43(3):509-512, 2013.

Santos, R.A.; Vargas Junior, F.M.; Seno, L.O.; Orrico, A.C.; Bottini Filho, F.D.E.; Senegalhe, F.B.; Cansian, K.; Longo, M.L. Biometria testicular de ovinos Pantaneiros alimentados com níveis crescentes de glicerina bruta na dieta. Revista Brasileira de Saúde e Produção Animal, 17(2):311-321, 2016.
Silva, D.J.; Queiroz A.C. Análise de alimentos: métodos químicos e biológicos. $3^{\mathrm{a}}$ ed. Viçosa: Minas Gerais, 2002. 235p.

Silva, V.O.; Lopes, E.; Andrade, E.F.; Sousa, R.V.; Zangeronimo, M.G.; Pereira, L.J. Use of biodiesel co-products (Glycerol) as alternative sources of energy in animal nutrition: a systematic review. Archivos de Medicina Veterinaria, 46(3):111-120, 2014.

Silva, K.M.; Zart, A.L.; Brum, K.B.; Fernandes, C.E.S. Histopathological and histomorphometric testicular characteristics associated to reproductive condition in Bos indicus (Nellore) bulls. Semina: Ciências Agrárias, 36(3):1935-1944, 2015.

van Cleef, E.H.C.B.; Almeida, M.T.C.; Perez, H.L.; van Cleef, F.O.S.; Silva, D.A.V.; Ezequiel, J.M.B. Crude glycerin changes ruminal parameters, in vitro green house gas profile, and bacterial fractions of beef cattle. Livestock Science, 178(6):158-164, 2015.

Van Soest, P.J.; Robertson, J.B.; Lewis, B.A. 1991. Symposium: carboydrate metodology, metabolism, and nutritional implications in dairy cattle. Journal of Dairy Science, 74(1):3583-3597. 